\title{
The Turn of Minimalism in Chinese Women's Clothing in the New Century
}

\author{
Junyi Cai ${ }^{1, \dagger}$, Ningxin Chen ${ }^{2, *},{ }^{*}$, Qiyue Dai ${ }^{3, \dagger}$ \\ ${ }^{1}$ School of Arts, Queen's University at Kingston, Ontario, Canada \\ ${ }^{2}$ School of Foreign Languages, University of Science and Technology Beijing, Beijing, China \\ ${ }^{3}$ Shanghai Jiao Tong University International A-Level Department, Shanghai, China \\ *Corresponding author email: 41909106@xs.ustb.edu.cn
}

These authors contributed equally.

\begin{abstract}
Minimalism plays an important role in the evolution of contemporary Chinese women's clothing. It is a clothing design style and a representative of the change of contemporary Chinese women's thinking and lifestyle. Especially in the new century, the birth and rapid development of mass media and post-modern consumerism have promoted the evolution and popularization of minimalism and its connotation. Under such circumstances, the trend has greatly influenced Chinese women's dress aesthetics, self-consciousness, and life concept. This paper will focus on analyzing this phenomenon and trace the development of minimalism in contemporary China.
\end{abstract}

Keywords: Minimalism, Contemporary China, Consumerism, Modern woman, Communication.

\section{INTRODUCTION}

Minimalism is a hot topic in the Chinese women's fashion industry in recent years. Minimalism represents not only an aesthetic concept but also a kind of lifestyle that Chinese women aspire to. Aesthetics is essentially a kind of spiritual and cultural activity of human beings. Lifestyle is the pattern that people exhibit about their activities and opinions [1]. Aesthetics and the lifestyle that people aspire to are interdisciplinary, and they are influenced by many variable factors, such as political economy, psychology, sociology, media science, history, culture, etc. They will constantly change with the change of times. These factors will ultimately contribute to the rise and fall of minimalism in women's fashion by changing society's aesthetics and desirable lifestyles.

Chinese society is an "unstable" society with many subversive social model changes in its history. However, the reform and opening in the 1980s is the most meaningful change because this is the first time Chinese women can choose their clothing style from consumers' perspectives. Furthermore, plentiful new social concepts emerged in the recent decades of economic prosperity after the reform, such as the rapid development of online media and so on. In conclusion, the factors affecting minimalism in contemporary China are extremely complex and changeable recently, which leads to the diversity and universality of minimalism in the Chinese female fashion industry.

\section{THE APPLICATION AND DEVELOPMENT OF MINIMALISM IN MODERN CHINESE FEMALE CLOTHING}

Minimalism was born in the Western world in the 1960 s and applied in the fashion industry [2]. Minimalism is famous for comfortable fabrics, simple design, and cutting [3]. However, under the comprehensive influence of China's politics, economy, urbanization, and mass media, women's clothing in modern China presents an alternating development trend of minimalism and anti-minimalism.

\subsection{Minimalism in Women's Dress in the Republic of China Period}

During the Republic of China, the cheongsam reflects that era's political and cultural background: Stepping into the modern society and learning from the west. The cutting of the cheongsam conforms to the basic features of minimalism. The development of the cheongsam was based on the continuous abandonment of the elaborate tailor-cutting elements of the garments of the Qing 
aristocratic women. For instance, in 1925, Shanghai women boldly cut off the sleeves and fat hem of the cheongsam to make a waistcoat cheongsam [4]. Due to the material shortage brought about by the Pacific War, the style and details of the cheongsam in the 1940s became more concise. The cutting of the cheongsam finally evolved into a tailor only with a piece of cloth can. However, the pattern and fabric of the cheongsam in the Republic of China period were anti-minimalist. People will choose expensive fabrics and complex patterns such as silk and Suzhou embroidery to show their status and particularity. Consumer culture will symbolize commodities, that is, the process of consumption and use of commodities as symbols to express certain meanings and information [5]. The symbols of early capitalism focused mainly on status and taste, resulting from large disparities in peace and a lack of resources [6].

It is worth noting that the minimalism in the cutting of the cheongsam is also the embodiment of "femininity". The cutting system of the Qing Dynasty flag has always been straight, with the chest, shoulders, waist, and buttock completely straight and slightly fat. And the modern cheongsam through the reduction of cloth and close-fitting design to make women's body and curvatures fully displayed. To stay sexy, Shanghai women gradually raise the slits of their robes to the hips so that lacy underpants reveal when young girls sit sideways. These exaggerated cheongsam designs fit the definition of a woman in a patriarchal society: an object of male sexual desire.

\subsection{Minimalism elements in the women's clothing of socialist China}

The female clothes that are widely used during the socialist era, including loose white shirts and Lenin suit, these two types of clothes have the following features, which echo the concept of minimalism is widely used in women's fashion in socialist China:

First, "Femininity" was broken by socialism after 1949, men's and women's clothing were unified, and women's clothing tended to be masculine. The socialist system reduced the difference between men and women in clothing design, especially during the Cultural Revolution. Socialism emphasizes equality between men and women, allowing women to participate in the field of industrial manufacturing. Gender-Neutral design is a hallmark for both Lenin coat and minimalism.

Second, Clothing after 1949 focused on practicality and comfort since China advocated a working-class lifestyle, so the pants and coat were designed to be loose and easy to move, which was in line with the design concept of minimalism: The human body is the best contour type. Therefore, there is no need for additional processing and modification in the design. Even if the waist is closed, it is not a deliberate performance, so most of them are H-shaped, cylindrical, etc.

Third, the style and color of shirts and Lenin suits were extremely simple. The whole dress usually has only one color, which is usually close to nature, including white, grey, green and blue. There are no extra decorations on the costume, only a few pockets, and buttons because socialist China promotes the social atmosphere of frugality. This is also in line with the basic characteristics of minimalism: save as many raw materials as possible, thus achieving environmental goals. Plus, complex decorations are used to symbolize class differences in capitalist society. Socialism emphasizes class integration, and everyone is equal, so costume decorations have no meaning of existence. All the flowery clothes, the cheongsam, became a symbol of capitalism and were banned by the government.

\subsection{The development of minimalism in female garments after China's reform and opening}

Minimalism in women's clothing declined in the first 20 years after reform and opening. People can finally choose their clothes freely. Like the "pressure cooker theory", the commodity economy, which was suppressed for too long, began to rebound, and anti-minimalism began to develop rapidly. For instance, exaggerated leopard-print blouses are prevalent in women's clothing. China has returned to the market economy, and clothing has been symbolized again. The symbols of clothing elements mainly represent economic status. The economic power of the wearer can only be reflected in the complexity of the craftsmanship of the garment or the fact that the fabric has more patterns than others. Like Thorstein Veblen mentioned in 18th century Britain, China has just taken the shadows of the poor. The rich people, including women entrepreneurs, are nouveau riche. They create social and cultural mechanisms. Veblen thinks that their wealth is new. To win society's identity, they are trying to imitate foreign aristocrats, engaged in "conspicuous consumption".

After 2000, the Chinese urban area stepped into a well-off society. For the first time, the Chinese urban area has transformed from a "production-oriented society" to a "consumption-oriented society." A large segment of society has acquired more material wealth than it needs. In Mike Featherstone's view, a post-capitalist modern society has been entered [7]. The symbolization of goods does not focus on the economic status matching with consumers but is a major means for individuals to show their own values and personality. Contemporary Chinese women are new cultural media people who pay attention to lifestyle. They take consumption as the center of their lives and establish their own social identity [8]. Minimalist clothing is a medium for Chinese women to express their lifestyle, which has a certain ideographic nature. Minimalism has become the mainstream value of 
urban Chinese women because the pressure brought by urbanization makes women yearn more for the simple lifestyle in the countryside. Women prefer to please their physical and psychological feelings through the choice of clothes, namely comfortable fabrics, such as light linen dresses.

The male-dominated society of "femininity influenced the minimalism of cheongsam cutting in the Republic of China". The minimalism of women's clothing in the socialist period is a forced political choice. After 2000, Chinese women can stand on the standpoint of consumers to choose a clothing style with strong autonomy.

\section{MINIMALISM IN WOMEN'S CLOTHING IN THE CONTEXT OF CONTEMPORARY CONSUMPTION}

As the minimalism mentioned above directly shows the change in the style of traditional Chinese clothing, from cheongsam to work clothes, women's selfawareness and consumption concept gradually sprout, forming a highly strengthened consumerism in the last stage. In clothing culture, minimalism is aiming to simplify complicated design and sales mode. Since the new century, Minimalism has updated from internal ideas, concepts, and outlines to the expression on clothing, which is also the reflux of minimalism. With women's higher status and clearer self-awareness, the production orientation has changed to the consumption orientation, and women's conscious self-choice of clothes has led to the return of minimalism.

The following text is the analysis and research in three categories of Minimalism: Traditional clothing, urban fashion, and work clothes, broadly divided until the near century.

\subsection{Minimalism in traditional dress}

Since the beginning of the new century, Chinese fashion has changed from clothes have magnificent texture to clothes that have simpler style, which is a return of Minimalism. It is about traditional Chinese clothing, which has a long history. The unique national feelings and symbolic cultural symbols of the Chinese people have attracted the whole world. Clothing design with "Chinese elements" as the theme has been an indispensable design symbol in the world clothing design industry since the beginning of the 20th century.

Under the guidance of today's consumerism, Chinese clothing is absorbing the minimalism of traditional culture to meet the needs of mass market consumption. Facing different consumer individuals, traditional clothing is reflected both in the brand and on the runway. For example, Shanghai Tang, a famous luxury brand in China, can be made into a Chinese version of "Chanel". Due to the luxury gene established in the early stage of the brand and the Chinese lifestyle and concept represented by it, "Shanghai Tang" has been equipped with favorable factors for the construction of luxury brands. Fashion Women's Wear Spring/Summer 2017 magazine invited international supermodel Sui $\mathrm{He}$ and some famous female figures to wear clothes of the "Shanghai Tang" brand. There was also a touch of minimalism in the sartorial choices on the Cannes red carpet on an international level. "For example, the famous Chinese movie star Fan Bingbing wearing a classic red dress embroidered with crane flying pattern and a bun appeared in the 64th Cannes Film Festival, showing the beauty of Chinese classicality. As the concept of minimalism continues to grow, in just a few short years, there has been a big change in clothing. In 2015, Fan Bingbing wore a pink silk strapless dress, which was very grand and simple.”[9]. The pure color showed the continuous advancement of minimalism, which also explained the exquisite and wonderful Chinese silk handicraft once again. It also reflects the appearance of high-end clothes on the traditional show and the development and influence brought by the integration of minimalism.

Thus it can be seen that the complex traditional clothing from the cage has changed with the minimalism to reflect the traditional skills in the clothing. A simple dress can be matched with different styles of retro classics, showing the unique temperament and elegance of women and reflecting Chinese culture at the same time.

\subsection{Minimalism in urban fashion}

Whether it's a mid-range brand or a high-end product, urban fashion has a prominent position in the women's wear market. It is often accepted by the majority of women [10]. The style of urban fashion has always been colorful to catch people's eye, but the recent rise of "break away from", "modern minimalist" ideas, so that the female urban culture road developed a simplified road.

The following is an example of the Taiping Bird brand for analysis. " Taiping bird 'clothing brand, in 2001, its brand won the first "China famous brand" title, 'Taiping bird' fashion leisure clothing was rated as the third favorite leisure brand of national consumers, which also means that it gradually began to occupy the Chinese market, in line with people's aesthetic concept. The more classic and impressive products include urban high-end business casual wear Pb series, mid-range fashion casual wear 'Taiping bird' series, new supermarket product BESPO series, urban professional women's office 'Taiping bird' fashion women's wear series, etc. Recently, for example, "Taiping Bird launched its spring/summer 2021 minimalist clothing line, which achieved revenue of 2.67 billion yuan in the first quarter, up $93.10 \%$ from the previous year."'11]. "Furthermore, significant data show that the "BESPO" series of the brand achieved a revenue of 5.521 billion yuan in the third quarter of 2020, with a year-on-year increase of $10.35 \%$. In addition, net profit 
reached 310 million yuan, an increase of $50.04 \%$ year on year." [12]. This is the mainline of the brand, with a minimalist style as the selling point. Pure color short sleeves and simple high-waisted running shorts for women are the most popular products. Thus, the essential reason for the success of the 'Taiping bird' brand is the use of minimalism in their design and the transformation of minimalism. Thus it can be seen that minimalism has a great impact on the design of clothing brands. In addition, the increase in the income of series of products and the promotion of domestic and international popularity is also minimalist products.

\subsection{Minimalism in workwear}

Minimalism is also found in workwear. Clothing has been carried out simultaneously in minimalism and antiminimalism, clearly reflected in the work clothes. "The work clothes not only have the continuation of minimalism but also have the presentation of antiminimalism." [13].Worker clothing has represented the normative rights system in China and has continued for a long time. However, there has been a trend of antiminimalism in uniforms and uniforms in today's era, which gradually evolved from the past just for practical purposes to meet the public aesthetic, and then more indepth performance in the display of personality. But in today's factory, clothing has evolved beyond just meeting the needs of the job. For example, semiconductor researchers' work clothes are not limited to protecting the safety and preventing laser damage. Their one-piece clothes include sandwich pockets, split pockets, waste pockets, multi-purpose hats, etc. Meanwhile, representative patterns and inspirational logos are added to the minimalist design. Anti-minimalism can mainly be understood as the simple design in the pattern, style, and other aspects. To consider the safety, labor, and production effectiveness, although it adds more factors and elements, its core is still the use of minimalism design.

Thus it can be seen that the minimalist thought will be partially retained, partly reversed, and partly maintained the diversified aesthetic. So the parallel of minimalism and anti-minimalism is all about satisfying the consumer market.

\section{INFLUENCE}

Due to the progress of women's autonomy and aesthetic concept in the new century, the development of minimalist clothing in contemporary China shows its rationality and universality. In this increasingly prevalent fashion, many elements of life have also been greatly affected.

First and foremost, from the elaboration of traditional Chinese clothing, urban fashion clothing, and uniforms, we can conclude that the clothing consumption of contemporary Chinese women is more consumerist, networked, and individualized-oriented. For our dress aesthetics, its evolution process represents the public's diverse understanding and needs of external beauty in different times and cultural backgrounds. With the development of urbanization and the liberation of mass thinking, women's subject consciousness and social status have been further enhanced, which leads to their aesthetic needs becoming more independent and diversified. Simultaneously, in the network transmission of minimalism, modern consumerism exerts a deeper impact on women's consumption desire for minimalist clothes. In terms of the above three kinds of clothing, both traditional and fashionable clothing draw more from the "blank space" in Western minimalism design and traditional Chinese thought. Although the uniform holds the reverse of minimalism to a certain extent, it also reflects the overall characteristics of more diversified and inclusive current minimalism aesthetics.

On balance, each era has its minimalist style in line with the public's aesthetic appreciation. While the definition of minimalism today is becoming more and more comprehensive, its form is becoming more extensive, reflecting the emergence of women's dominant position. Featherstone once pointed out that in the context of consumer society, the body has been loaded with more meanings. It is no longer confined to organs and limbs but given more symbolic meanings. [14] Such symbolization affected people's exaggerated understanding of the most basic concept of "beauty" at once. Still, after that, the extreme simplification of women's clothing has to some extent revealed people's introspection on the increasingly complicated contemporary clothing style and life. The most important remolding of this simplified trend of thought for the concept of clothing lies in highlighting the beauty of the body and nature. The focus of clothing has already completed the transfer from external decoration to female subjectivity.

This aesthetic concept of "less is more" has thus been reflected in reshaping Chinese female aesthetics. First, due to the comfortable and natural characteristics of minimalist clothing compared with the complex design, its requirements and constraints on the female body are greatly reduced. Second, the single belief that the primary feature of women's clothing was to accentuate the feminine figure was vigorously attacked. Women are less obsessed with external beauty factors and more aware of the fact that confidently expressing the relationship among the logic of nature, the material of the clothing, and the body itself through their daily dress can much more reveal the self-reliance and self-improvement of their state. As an expression tool of feminists, fashion has been breaking through the narrow definition of "what is female beauty" for nearly a hundred years. Contemporary Chinese women have formed a new understanding of 
"femininity" in the process of their rising dominant position in both ideology and economy. That is, when women do not have to rely too much on external decoration to achieve gender recognition, their external expression will naturally be closer to their hearts. This also promotes the diversity of the development of female beauty. The liberation of clothing interacts with the liberation of the mind, and minimalism is the external expression of such a process.

In terms of media society, cultural communication systems, such as social networks, exert a mutual effect on minimalism and create new aesthetic and life concepts. As one of the sales channels of products, the Internet plays a great role in guiding people's daily consumption tendency with its advertising copy and the publicity of consumption concept. Meanwhile, this trend of minimalist values rapidly influences the public's aesthetics through mass media such as social networks and the film and television industry, such as the variety show "The Wanted Life" or the minimalist dressing style popular on WeChat official accounts. In a word, minimalist clothing is a medium for Chinese women to express their lifestyle, which has a certain ideographic nature. At the beginning of China's commercialization, postmodernism and consumerism played a huge role in the "second world" created by media. Due to the limited scope of cognition, people's consumption has been greatly affected by complex factors such as advertisers' marketing methods. In contemporary society, the globalization of social media has facilitated the spread of liberal ideas. Chinese women have been influenced by Western minimalism and found their subjectivity in the active global feminist movement. Their fashion ideas are being rewritten little by little in the constant social discussion. They begin to desire to return to the origin of life and material, to eliminate the superfluous ingredients, in exchange for more time, space, and freedom of thought. At present, with the support of feminism, minimalism, and modernism, the minimalist trend of Chinese contemporary women's clothing further deconstructs and recreates the real aesthetics of life, which is pure, inclusive, and pluralistic.

Thoreau once said, "Our life is frittered away by detail. Simplify, simplify." Simplifying our clothes and lives is a necessary way to get rid of distractions and discover the essence of life since one of its most important queries is "What really matters?". This kind of questioning brings clarity to the context of life. In other words, minimalism is about letting us blow off the bubble and focusing on the crucial things in life. Therefore, to this extent, minimalist clothing undoubtedly coincides with Thoreau in its starting point. Minimalism is about letting us blow off the bubble and focus on the crucial things in life.

\section{CONCLUSION}

From the perspective of the development of the times and the discussion of the three clothing styles, as a conclusion: Chinese women's lifestyle and aesthetic habits have been changing. From simple to gorgeous and then to inclusive and diverse, this developing course reflects the spiral rise of fashion concepts. To sum up, the simplification of Chinese women's clothing has a significant influence and interaction on clothing aesthetics, femininity, and life concept. In this process, clothing is the carrier of ideas, and mass media and public discussion are the means of their transmission and reshaping.

\section{REFERENCES}

[1] Aiholtll. (2013, June 29). The concept, content and structure of lifestyle. Baiduwenku. https://wenku.baidu.com/view/647403b50029bd64 783e2cb8.html.

[2] Chave, A. C. (2000). Minimalism and Biography. The Art Bulletin, 82(1), 149-163. https://doi.org/https://www.jstor.org/stable/305136 8 ? seq $=1$

[3] Pater, R. (2021, February 18). What Is Minimalist Fashion? And Is It The Key To A Happier And More Sustainable Lifestyle? Good On You. https://goodonyou.eco/minimalist-

fashion/\#: :text=Minimalism $\% 20$ is $\% 20$ about $\% 20 \mathrm{~s}$ tripping $\% 20$ back,narrative $\%$ E2\%80\%94and $\% 20$ fo r\%20good\%20reason.

[4] Song, D., \& Wang, J. (2020). Study on Women's Clothing Changes in the Republic of China Period. Northeast Dianli University, 14, 159-160. https://doi.org/https://kns.cnki.net/kcms/detail/detai 1. asp $\mathrm{x}$ dbcode $=\mathrm{CJFD \& dbname}=\mathrm{CJFDLASN} 2020$ $\&$ filename $=$ MDAN202014077\&v $=$ alq01XAJc6kM XLMLfuxpSN1IWA6BkUNFIkb5sGYGa6O55eA $8 \mathrm{Uuauwuh} 2 \mathrm{z} 7 \mathrm{bvDuUj}$

[5] Lin, D. (2020, November 24). A peek into Chinese consumer culture. 360doc. http://www.360doc.com/content/10/1124/19/53574 9_72115260.shtml.

[6] Obukhova, E., Zuckerman, E., \& Zhang, J. (2014). When Politics Froze Fashion: The Effect of the Cultural Revolution on Naming in Beijing. American Journal of Sociology, 120(2), 555-583. doi:10.1086/678318

[7] Kong, X. (2008). Military Uniform as a Fashion during the Cultural Revolution. Intercultural Communication Studies XVI, 2. https://doi.org/https://web.uri.edu/iaics/files/24Xurong-Kong.pdf 
[8] Su, Q. (2009). Featherstone, Michael. Consumer Culture and Postmodernism. Northwest Normal University.

[9] Global entertainment and fun. Fan Bingbing Looks on the Cannes Red Carpet for 7 Years, 9 June 2018, mr.baidu.com $/ \mathrm{r} / \mathrm{nhAYoHRTS} 8 ? \mathrm{f}=\mathrm{cp} \& \mathrm{u}=33 \mathrm{faaec} 45$ b1c6787.

[10] Changjiang River Daily. The "Red Carpet" in Cannes Is a Glory for the Country, 24 May 2013, weifang.dzwww.com/yl/201305/t20130524_84212 33.htm.

[11] " Bird Dress. " 3 , http://www.chinaef.com/ladies/brand/peacebird/products.html

[12] The Customer Thought, blog.linkshop.com.cn/u/85402/326816.html.

[13] Global entertainment and fun. Fan Bingbing Looks on the Cannes Red Carpet for 7 Years, 9 June 2018, mr.baidu.com $/ \mathrm{r} / \mathrm{nhAYoHRTS} 8 ? \mathrm{f}=\mathrm{cp} \& \mathrm{u}=33 \mathrm{faaec} 45$ b1c6787.

[14] Mike Featherstone. (2007), Consumer Cultural and Postmodernism (Second Edition), London: Sage Publications

https://kns.cnki.net/kcms/detail/detail.aspx?dbcode $=\mathrm{CDFD} \&$ dbname $=$ CDFDLAST2017\&filename $=1$ 017003906.nh\&v=eePLMXURJBIKCXBkrwBwC G2ambexmGXHXtzVPkKUONNPypKoqletsvO5jI siPEII 